\title{
MiR-34a Promotes Apoptosis and Inhibits Autophagy by Targeting HMGB1 in A ute Myeloid Leukemia Cells
}

\author{
Liru Liu ${ }^{\mathrm{a}}$ Weihua Ren ${ }^{\mathrm{a}}$ Kuisheng Chen ${ }^{\mathrm{b}}$
}

aDepartment of Clinical Laboratory, Luoyang Central Hospital Affiliated to Zhe Luoyang, bepartment of Pathology, the First Affiliated Hospital of China

\section{Key Words}

miR-34a • HMGB1・ Apoptosis • Autophagy •

\section{Abstract}

Background: MiR-34a is identified as a tumor leukemia (AML) development. Howeve unclear. Methods: The expression of $m$ detected by qRT-PCR and western bl 34a mimics, miR-34a inhibit The apoptosis and autophag? western blot, respectively oini

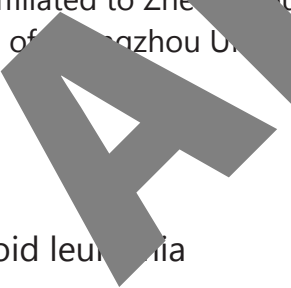
applied to predict and HMGB1 on chemothera with all-trans retinoir-acic. ry the tu, $i$ of miR-34a. The effects of miR-34a mimics or sinduc autophagy were further explored in $\mathrm{HL}-60$ cells treated A. Results: MiR expressed in $\mathrm{H}$ of of MiR-34 lower expressed and HMGB1 mRNA and proteins were both higher inhibite opha

-1 cells compared with that in HS-5 cells. Higher expression levels ie nine 2000 was used to transfect with miRNA 3.1-HMGB1, and corresponding controls. AL-60 and THP-1 cells. Dual luciferase reporter system confirmed that HMGB1 potential target of miR-34a. Moreover, overexpression of HMGB1 dramatically ed th motion of apoptosis and inhibition of autophagy mediated by higher ion lev of miR-34a. Higher expression level of miR-34a and lower expression level of inhibited chemotherapy-induced autophagy by stimulating the LC3 conversion. cluston: MiR-34a promoted cell apoptosis and inhibited autophagy by targeting HMGB1. cluston: MiR-34a promoted cell apoptosis and inhibited autophagy by targeting
fore, miR-34a may be a potential promising molecular target for AML therapy. nf fore, miR-34a may be a potential promising molecular target for AML therapy.
02017 The Author(s)

\section{Introduction}

Published by S. Karger AG, Basel

Acute myeloid leukemia (AML), the most common acute leukemia in adults and a lethal hematological malignancy originated from myeloid progenitor cells, is characterized L. Liu and W. Ren contributed equally to this work.

\begin{tabular}{ll}
\hline Liru Liu & Department of Clinical Laboratory, Luoyang Central Hospital Affiliated to Zhengzhou \\
& University, No. 288 Zhongzhou Road, Xigong District, Luoyang 471000 (China) \\
& Tel. +86-0379-63892166, E-Mail klirucb@163.com
\end{tabular}


by the uncontrolled proliferation, diverse clinical presentations and accumulation of dysfunctional hematopoietic progenitors along with blockage in normal hematopoiesis $[1,2]$. Chemotherapy with hematopoietic stem cell transplantation for AML is the main treatment and preferred therapy [3]. Along with the high relapse rates in AML patients, the overall 5 year survival rate remains poor, apprpximately 30\%-40\%, although great advanc in medicine and chemotherapy have been achieved [4]. The main cause of therapeuti failure and poor outcomes is the occurrence of chemotherapy resistance in leukemia cell [5]. Therefore, alternative therapies are urgently needed for patients with AML.

MicroRNAs (miRNAs) consist of a class of small noncoding regulatory RNA - of 19 nucleotides (nt) that are highly conserved [6]. MiRNAs negatively modulate ge. cxpres at the post-transcriptional level by interacting with 3'-untranslated regions (3'-UT target gene mRNA, leading to mRNA degradation or translational repress ${ }^{j}$ $[7,8]$. Accumulating evidence has demonstrated that miRNAs are closely as regulation of cellular differentiation [9], cell proliferation [10], apoptosis, ${ }^{1}$ angiogenesis and carcinogenesis in various tumors [12]. In addition, $m$ as an important regulator of autophagy, a lysosomal-mediated path at contributes to degradation of cell waste proteins and damaged organelles herous s have revealed that aberrant expressions of miRNAs are involved in AN a r asis a development. For example, Favreau et al. found that miR-199b functio as $r$ suppressor and had prognostic significance in AML [13]. Huang et al. shon 4 mi. -519 enhanced cell proliferation and induced cell apoptosis in AN HL-60 cell by decreasing the level of RNA-binding protein human antigen R [14]. Mih is the first ntified tumor suppressor gene that is lower expressed in many forms of toncluding breast cancer, lung cancer and AML [15-17]. MiR-34a plays a critical ro $n \mathrm{~m}$. ellular processes including p53induced cell cycle arrest, apoptosis and other ogis ehaviors by negatively regulating its target genes $[18,19]$. However, the chanism of miR-34a in AML is still unknown.

High mobility group box 1 (HMGl DNA mismatch and regulate tre ns. HMGB1 is higher expressed in various types of tumors and is close ciate with the inflammatory response, angiogenesis, tumor cells growth, invas an [20-22]. It has been manifested that HMGB1 overexpression inhibite ell apop_s, induced cells growth and functions as an antiapoptotic protein in leul ia [2? Additionally, HMGB1 improved chemotherapy resistance to anticancer drugc $h_{y}$ in. cophagy in human myeloid leukemia cells [24]. Therefore, targeting HMGP a crucial underlying application in leukemia treatment.

In this st $y$, ession level of miR-34a and HMGB1 were investigated in AML cells. Furth mor he nects of miR-34a on cell apoptosis and autophagy and the potential mechar vere r investigated in AML cells.

\section{Materı. nd Methods} and culture

The numan leukemia cell lines HL-60 and THP-1 were obtained from the Institute of Hematology China Academy of Chinese Medical Sciences (Beijing, China) and the human normal stromal cells were purchased from American Type Culture Collection (ATCC, Manassas, VA, USA). All cells were altured in complete medium (RPMI-1640; Invitrogen, Grand Island, NY, USA) supplemented with 10\% heat-inactivated fetal bovine serum (FBS) (Invitrogen), penicillin $(100 \mathrm{U} / \mathrm{mL}) /$ streptomycin $(100 \mu \mathrm{g} / \mathrm{mL})$ (Invitrogen), and $2 \mathrm{mM} \mathrm{L-glutamine} \mathrm{in} \mathrm{a} \mathrm{humidified} \mathrm{air} \mathrm{at} 37^{\circ} \mathrm{C}$ with $5 \% \mathrm{CO}_{2}$.

\section{Cell transfection and treatment}

The synthetic miR-34a mimics, anti-miR-34a and negative control (miR-control) were obtained from GenePharma (Shanghai, China). SiRNA targeting human HMGB1 (si-HMGB1), siRNA control (si-control), pcDNA 3.1-HMGB1, and pcDNA 3.1-control were purchased from Ribobio (Guangzhou, China). After HL-60 and THP- 1 cells $\left(5 \times 10^{5}\right.$ cells/well) were cultured in 6 -well plates for $24 \mathrm{~h}$, miRNA mimics, miRNA inhibitor, 


\section{Cellular Physiology and Biochemistry \\ Cell Physiol Biochem 2017;41:1981-1992 \\ DOI: 10.1159/000475277 \\ Published online: April 13, 2017 \\ (c) 2017 The Author(s). Published by S. Karger AG, Base \\ www.karger.com/cpb \\ Liu et al.: MiR-34a Inhibits Acute Myeloid Leukemia Cells}

si-HMGB1, pcDNA3.1-HMGB1 or corresponding controls were transfected into HL-60 and THP-1 cells by Lipofectamine 2000 reagent (Invitrogen) in accordance with the manufacturer's protocol, respectively. To assess autophagic flux under a stressed condition (chemotherapy), HL-60 cells transfected with miR-34a mimics or si-HMGB1 were treated with $1 \mu$ M ATRA (Sigma, St. Louis, MO, USA) for 24 or $48 \mathrm{~h}$. Lysosomal

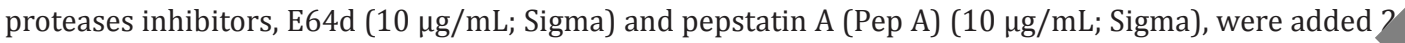
before protein extraction, followed by western blot analysis of the LC3 proteins.

\section{Quantitative real-time PCR ( $q R T-P C R)$}

Total RNA was extracted from collected cells by using Trizol (Invitrogen) and an Agilent Bioanalyzer (Agilent Technologies, Inc., Santa Clara, CA, USA) was used to check isolated RN ality. RNA (500 ng) was reversely transcribed into cDNA by miRNA-specific TaqMan miRNA assay Biosystems, Foster City, CA, USA). qRT-PCR was performed by the SYBR® Premix Ex Ta`TMII ( Time, Takara, Dalian, China) on a CFX 96 real-time PCR thermocycler (TaKaRa) to levels of miR-34a. U6 small nuclear RNA was used as the internal control for miR-34a $34 \mathrm{a}$ amounts were performed using the $2^{-\Delta \Delta c t}$ method. The conditions of qRT-PCF follows: $92^{\circ} \mathrm{C}$ for $10 \mathrm{~min}$, followed by 40 cycles at $92^{\circ} \mathrm{C}$ for $10 \mathrm{~s}$ and $60^{\circ} \mathrm{C}$ for 1 were as follows: forward 5'-GCCCTGGCAGTGTCTTAG-3' and reverse 5'“AGTGCG'

\section{Western blot assay}

HL-60 and THP-1 cells were collected at $48 \mathrm{~h}$ post-transfection a ch extraction lysis buffer (Thermo Scientific, Hudson, NH, USA) for $30 \mathrm{~m}$ from collected cells with RIPA lysis buffer (Zhong-Sha? iao, Beijing, $C$ evaluated by BCA protein assay kits (CoWin Biotechnolo $(40 \mu \mathrm{g})$ were subjected to $10 \%$ SDS-PAGE and subse membranes (PVDF; Millipore, Boston, MA, USA). Ther $1 \mathrm{~h}$ and incubated with primary antibodies (HMGB1 Atg5 antibody, LC-3I antibody, and LC-3II USA) and $\beta$-actin (1:3,000; Santa Cruz Biote incubation, the membranes were urther conjugated secondary antibody chemiluminescence using the ECL

iiing China Prom cn total protein was extracted he miR-sra primers 'GGAG T-3'. nsferred onto polyvinylidene difluoride branes were blocked with $5 \%$ milk for xantibody, Bcl-2 antibody, CytC antibody, Cell Signaling Technology, Danvers, MA, not Inc., Santa Cruz, CA, USA). Followed by $4{ }^{\circ} \mathrm{C}$ overnight d the appropriate horseradish peroxidase (HRP)(ology) and the protein bands were visualized by

Dual luciferase reporte

The fragments of 3'-1 binding sites of miR-34a pre downstream of fir The constructed 1 ff HMGB1-MUT ror lu as

(Millipore Corp., Billerica, MA, USA).

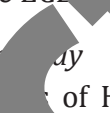
of HMGB1 mRNA containing the wild-type (wt) and the mutant (mut) argetscan (http://www.targetscan.org/) [25] were cloned into the ras ang gene in the pMIR-Report vector (Ambion Inc., Austin, TX, USA). orters were called as pMIR-LUC-3'-UTR-WT HMGB1 and pMIR-LUC-3'-UTRconfluenc ay, when HL-60 and THP- 1 cells $\left(5 \times 10^{4}\right)$ were grown in 24 -well plates to $80 \%$ or miR-control (100 nM) were cotransfected with reporters plasmids (100 ng) THP-1 cells by Lipofectamine 2000 (Invitrogen). The luciferase activities were measured by e Du viferase kit (Promega, Madison, WI, USA) after $48 \mathrm{~h}$ transfection. Cells transfected with vMIR-c crol vector was used to check transfection efficiency and Renilla luciferase was used as norn. control.

\section{Cell apoptosis}

ell apoptosis was assayed using a commercially available Annexin V/FITC and PI apoptosis detection (nvitrogen) and flow cytometry. Briefly, the transfected HL-60 and THP-1 cells were trypsinized, harvested, washed and resuspended with $100 \mathrm{ml}$ of $1 \times$ binding buffer at a final concentration of $1 \times 10^{6}$ cells/ml. Then the cells were stained with $5 \mu \mathrm{l}$ Annexin V/FITC followed by $1 \mu \mathrm{lPI}$ and incubated in the dark for 15 min at room temperature. The apoptotic cells were analyzed by FACSCalibur flow cytometer (FACScalibur, BD, Franklin Lakes, NJ, USA).

\section{Statistical analysis}

The data are showed as the mean \pm SD from three independent experiments. Statistical analysis was carried out with Student's $t$-test or analysis of variance using Graphpad Prism 5 (GraphPad Software, Inc., San Diego, CA, USA). Differences with $P$ values of $<0.05$ were considered to be statistically significant.

\section{KARGER}




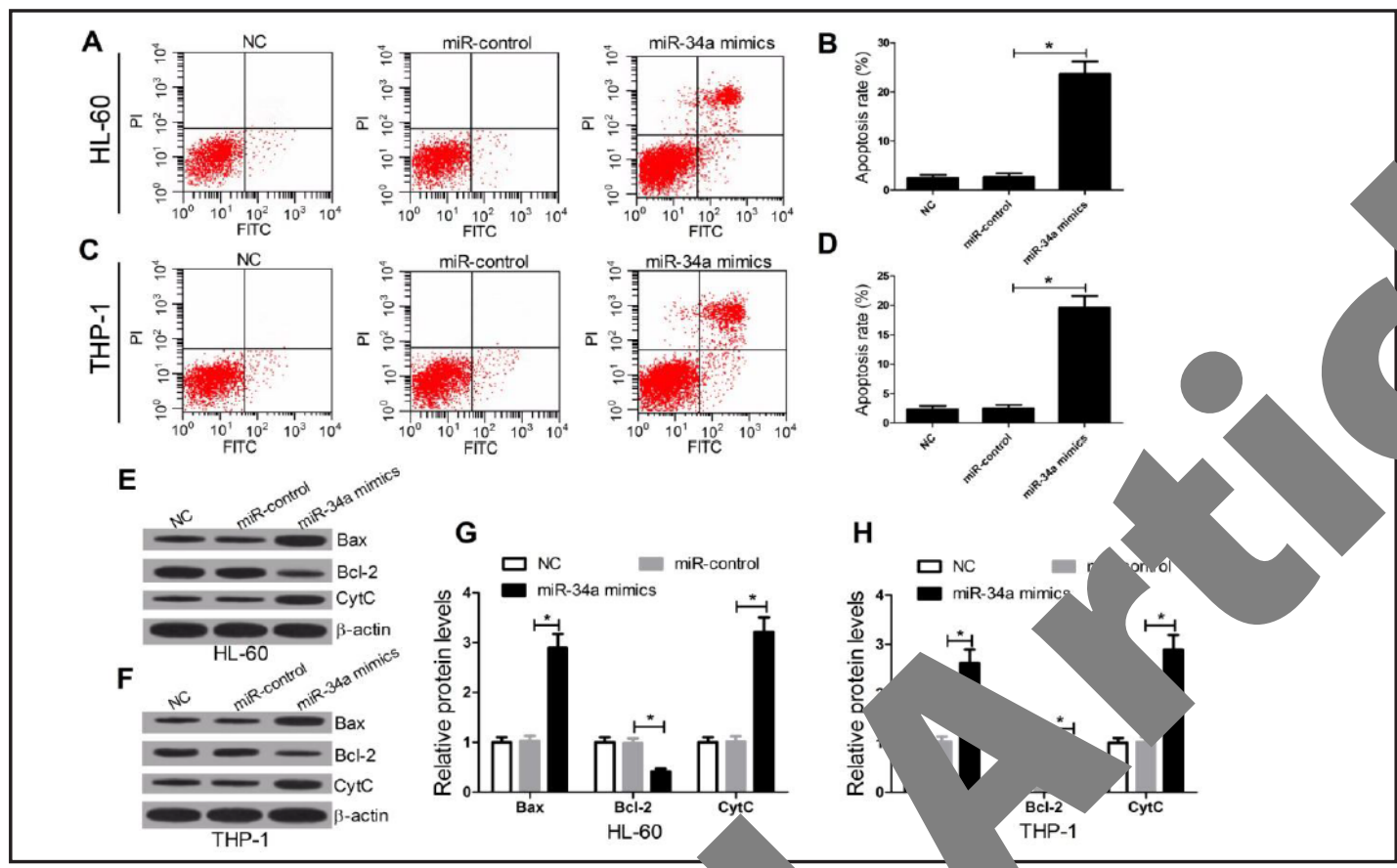

Fig. 2. Effects of higher expression levels of miR-34a o miR-34a mimics or miR-control and cultured for $48 \mathrm{~h}$. TD) cells was evaluated by flow cytometry using an An $\mathrm{nV} / \mathrm{A}$ ciated proteins Cyt-C, Bax, and Bcl-2 in HL-60 (E and C TH blot and normalized to $\beta$-actin. Data are prese $* P<0.05$.

cells apop s. Cells were transfected with sis of HL-60 (A and B) and THP-1 (C and ction kit. The levels of apoptosis-asso-

$r$ and $\mathrm{H}$ ) cells were analyzed by western
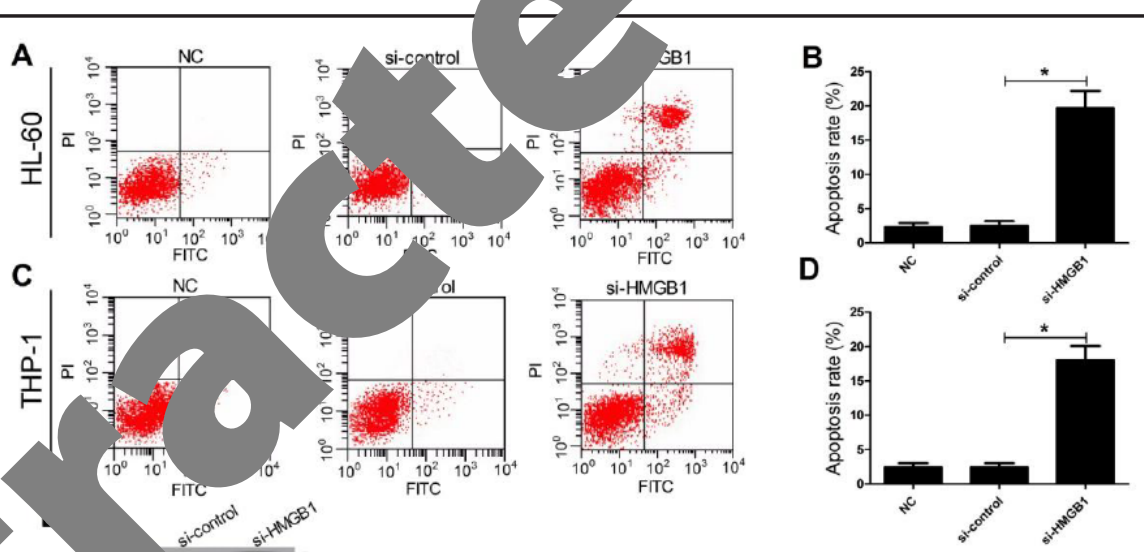

H
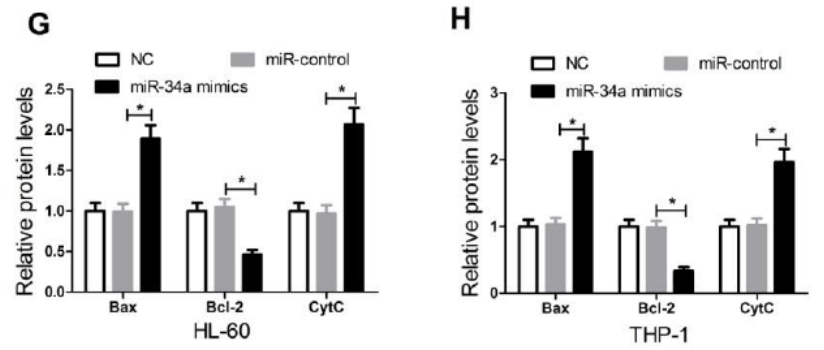

Fig. 3. Effects of lower expression levels of HMGB1 on AML cell apoptosis. Cells were transfected with si-HMGB1 or si-control and cultured for 48h. The apoptosis of HL-60 (A and B) and THP-1 (C and D) cells was evaluated by flow cytometry using an Annexin V/PI detection kit. The levels of apoptosis-associated proteins Cyt-C, Bax, and Bcl-2 in HL-60 (E and G) and THP-1 (F and H) cells were analyzed by western blot and normalized to $\beta$-actin. Data are presented as mean \pm SD $* P<0.05$. 
Fig. 4. Effect of higher expression levels of miR34a on AML cell autophagy. Cells were transfected with miR-34a mimics or miR-control and cultured for $48 \mathrm{~h}$. Western blot was used to detect the expression levels of Atg5, LC-3I and LC-3II in HL-60 (A and $\mathrm{B}$ ) and THP-1 (C and D) cells. $\beta$-actin was used for normalization. Data are presented as mean SD. $* P<0.05$.

Fig. 5. Effect of lower expression levels of HMGB1 on AML cell autophagy. Cells were transfected with si-HMGB1 or si-control and cultured for $48 \mathrm{~h}$. Western blot was used to detect the expression levels of Atg5, LC-3I and LC-3II in HL-60 (A and B) and THP-1 (C and D) cells. $\beta$-actin was used for normalization. Data are presented as mean $\pm \mathrm{SD}$. ${ }^{*} P<$ 0.05 .
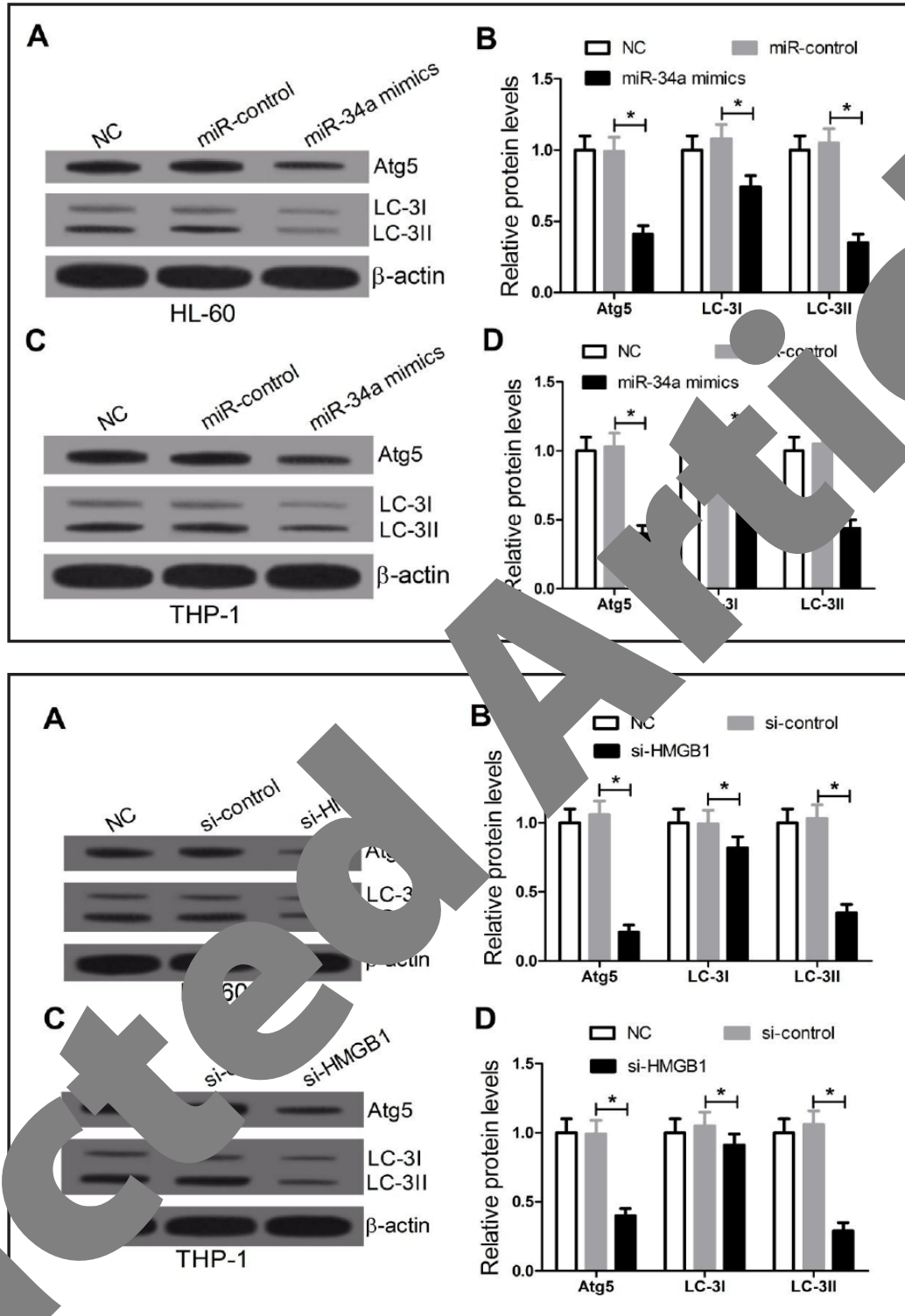

ression level of miR-34a inhibited autophagy of AML cells

(iR-34 mics were used to study the effect of higher expression level of miR-34a on A 10 to hagy. The levels of autophagy-related proteins Atg5 and autophagy marker -31 -3II were detected by western blot. The results revealed that higher expression el of miR-34a both in HL-60 cells (Fig. 4A and 4B) and THP-1 (Fig. 4C and 4D) cells ar atically decreased the levels of Atg5, LC-3I and LC-3II. The conversion of the cytosolic $n$ of LC-3 (LC-3I) into the active membrane-bound form of LC-3 (LC-3II) in miR-34a group was also decreased in comparison with that in miR-control group.

Lower expression level of HMGB1 inhibited autophagy of AML cells

Si-HMGB1 was used to evaluate the effect of lower expression level of HMGB1 on autophagy of AML cells. The western blot results showed that the levels of Atg5, LC-3I and LC-3II as well as the conversion of LC-3I into LC-3II in HL-60 (Fig. 5A and 5B) and THP-1 (Fig. 5C and 5D) cells were both obviously reduced in si-HMGB1 group compared with that in si-control group. 
MiR-34a inhibited autophagy by targeting HMGB1 in AML cells

To study whether miR-34a inhibited autophagy by binding to HMGB1 in AML cells, miR34a mimics were cotransfected with pcDNA 3.1-HMGB1 or pcDNA 3.1-control into HL-60 cells to investigate their effect on the expression of autophagy-related proteins Atg5, LC-3I 
A

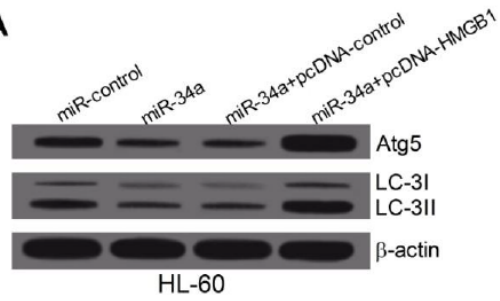

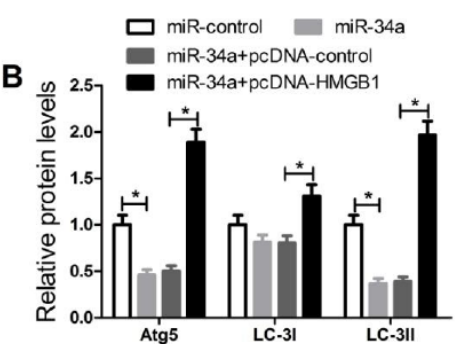

Fig. 7. Overexpression of HMGB1 reversed the inhibition effects of miR-34a on autophagy $\overline{y^{\prime}-60}$ Cells were cotransfected miR-34a mimics with pcDNA 3.1-HMGB1 or pcDNA 3.1-control and 48 h. (A) Western blot was used to detect the expression levels of Atg5, LC-3I and LC-? Quantification analysis of proteins Atg5, LC-3I and LC-3II in HL-60 cells. Each group wa independent experiments. Data are presented as mean SD. ${ }^{*} P<0.05$.
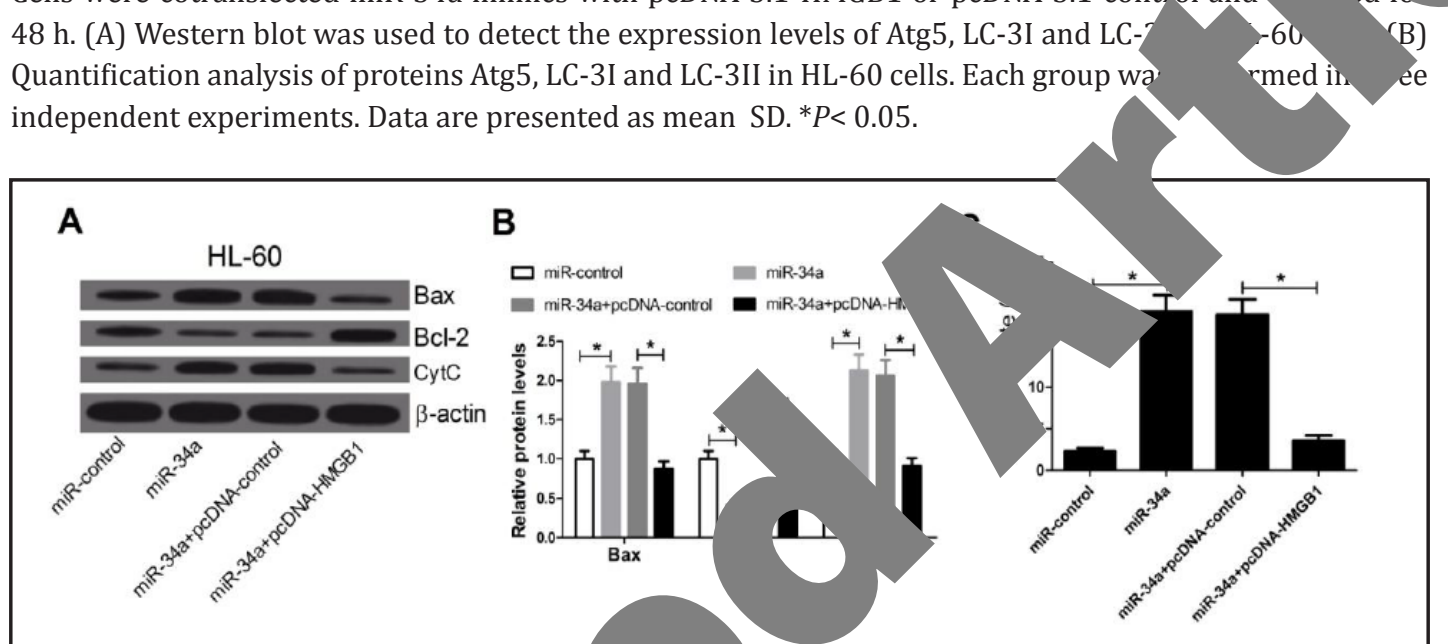

Fig. 8. Overexpression of HMGB1 gverturn Cells were cotransfected miR-34a h. (A and B) The expression levels 7 on effects of miR-34a on apoptosis in HL-60 cells. 1-HMGB1 or pcDNA 3.1-control and cultured for 48 normalized to $\beta$-actin. (C) The opio 50 cells was evaluated by flow cytometry using an Annexin V/PI detection kit. Each gro vas perm a in three independent experiments. Data are presented as mean \pm SD. ${ }^{*} P<0.05$.

and LC-3II. The indicated that the miR-152 overexpression significantly decreased the levels of A o, -3II, as well as the conversion of LC-3I into LC-3II in HL-60 cells, which was amp lverturned by HMGB1 overexpression (Fig. 7A and 7B), suggesting that re sion of HMGB1 by pcDNA 3.1-HMGB1 significantly relieved the i' hibitor. ct of miR-34a on autophagy in HL-60 cells.

R-34a whibited cell apoptosis by targeting HMGB1 in AML cells

sptosis of AML cells with the same treatment as above was assessed by flow metry. The results showed that the expression levels of Cyt-C and Bax were markedly 1C sed and Bcl-2 was conspicuously decreased by higher expression level of miR-34a . L-60 cells, which was strikingly overturned by HMGB1 overexpresssion by pcDNA .1-HMGB1 (Fig. 8A and 8B). In addition, HMGB1 overexpression by pcDNA 3.1-HMGB1 significantly attenuated the promotion of apoptosis caused by higher expression levels of miR-34a (Fig. 8C).

Higher expression level of miR-34a and lower expression level of HMGB1 both inhibited all-trans retinoic acid (ATRA)-induced autophagy in AML cells via stimulating the LC3 conversion

To further investigate the effects of high expression of miR-34a or low expression level of HMGB1 on autophagy under a stressed condition (chemotherapy), HL-60 cells transfected 

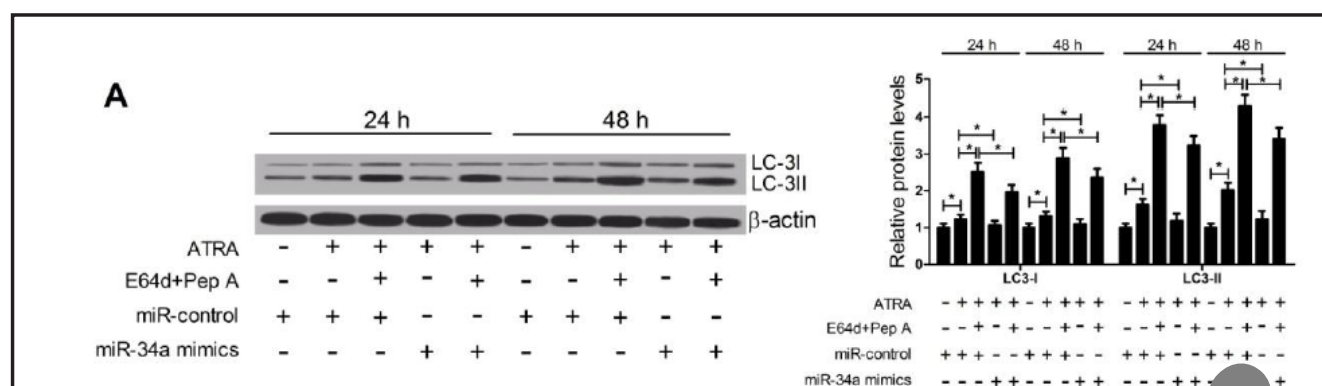

B
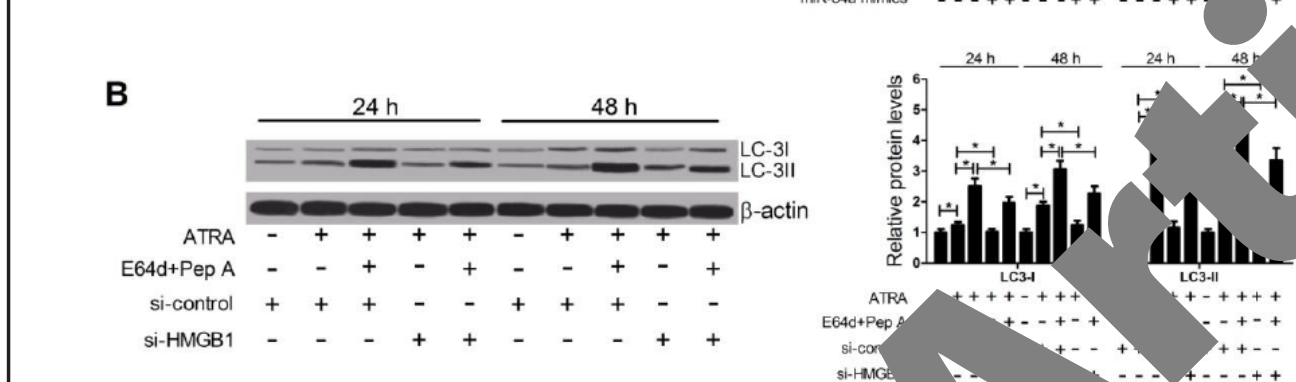

Fig. 9. Effect of miR-34a mimics or si-HMGB1 on AML cell autophag, E64d and Pep A. The levels of LC-3I and LC-3II in HL- ells transfect (B) th miR-34a mimics (A) si-HMGB1 (B) were examined by western blot. HL-60 cells $\mathrm{s}$ ted with $\mathrm{m}$ ta mimics or si-HMGB1 were treated with $1 \mu \mathrm{M}$ ATRA for 24 or $48 \mathrm{~h}$. E64d $(10 \mu \mathrm{g} / \mathrm{mL}) \quad$ A $(10 \mu \mathrm{g} / \mathrm{mL})$ were then added $2 \mathrm{~h}$ before protein detection. Data are presented as mean \pm SD. $*$

with miR-34a mimics or si-HMGB1 w proteases inhibitor E64d and pepstati lysosome. As shown in Fig. $9 A$ and 9 the autophagosome-specific si-HMGB1 both significantly .05.) E64d + Pep A, suggesting thession level of miR-34a or lower expression level of HMGB1 markedly sup ssed ch_therapy-induced autophagy. More interestingly, we noticed that LC-3II cons ous ' accumulated in the presence of E64d + Pep A under the chemotherapy condition, sthat the accumulation of LC-3II was due to the stimulation of the LC3 cony ut rou due to the inhibition of the fusion of autophagosome with lysosome. Tak if of hese results revealed that higher expression level of miR-34a and lower expr sion el miMGB1 both inhibited ATRA-induced autophagy in AML cells via stimulat ne LC version.

\section{iscuss.}

NAs have drawn more attention during the past few years due to the effect of NAs in AML pathogenesis and its availability in early diagnosis and prognosis of AML. ${ }_{4 i} 4$ family, including miR-34a, miR-34b and miR-34c, is a type of conserved miRNAs -ly distributed in mammals and is involved in AML development [26]. Many researchers rave investigated the role of miR-34 family in leukemia, especially miR-34a. For instance, $\mathrm{Li}$ et al. reported that miR-34b was significantly lower expressed in AML blood samples and AML cell lines, and miR-34b inhibited cell viability and promoted cell apoptosis in AML cells by targeting HSF1 [27]. Yang et al. showed that miR-34c was lower expressed and served as a biomarker in predicting prognosis in patients with AML [28]. Wang et al. reported that miR-34a expression was reduced and acted as a tumor suppressor and a potential immunotherapeutic target by targeting PD-L1 in AML [17]. Zauli et al. found that miR-34a decreased the levels of oncogenes E2F1 and B-Myb in leukemic cells [29]. Ichimura et al. showed that miR-34a suppressed cell proliferation by inhibiting mitogen-activated KARGER 
protein kinase kinase 1 (MEK1) during megakaryocytic differentiation of chronic myelocytic leukemia cell line K562 [30]. In the present study, in accordance with previous reports, we demonstrated that miR-34a expression was significantly decreased in HL-60 and THP-1 cells compared with that in HS-5 cells and miR-34a overexpression by miR-34a mimics promoted cell apoptosis and inhibited cell autophagy, suggesting that miR-34a plays a crucial role AML progression.

Recent reports showed that higher expression level of HMGB1 contributed to tumourigenesis and the development of cancers. For example, Huber et al. reported ${ }^{\prime}$ HMGB1 played an important role in murine B16 melanoma growth and metastasis $\mathrm{Xi}$ et al. found that HMGB1 knockdown and cordycepin had synergistic effect apoptosis, inhibiting proliferation and adhesion in chronic myeloid leukemia ce our study, HMGB1 protein and mRNA was found to be higher expresser $n$ compared with human bone marrow stromal cell line compared with human bon th HMGB1 by si-HMGB1 significantly promoted cell apoptosis and suppr ss ang in AML cells.

More importantly, the present study demonstrated that HMG binding target of miR-34a by Targetscan, which was furt confirme dual luciferase assay. Besides, it was verified that miR-34a targetedly re exp on HMG1. In addition, it was found that miR-34a promoted cell apop s a sed autophagy by targeting HMBG1. Moreover, the study further revealed that ex $x_{r}$ ession level of miR34a or lower expression level of HMGB1 could ppress che erapy-induced autophagy via stimulating the LC3 conversion. It has been rted that lower expression level of miR-34a in cervical and colorectal tissues had ar correlation with HMGB1 levels and higher expression level of miR-34a inhibited $1 \mathrm{p}$ ration, migration and invasion in human cervical and colorectal cancer by targe

Previous studies have demonstrat a is a direct downstream target of p53, which is a tumor suppressor os inscriptional targets regulate cell cycle, cell senescence, DNA repair, apoptosis a er plogical behaviors [34, 35]. The p53-miR34a network plays a crucial esis. For example, perturbation of miR-34a expression contributed to tur snesis oy strongly attenuating p53-mediated apoptosis in human cancers [36]. In ad tion, $\quad s$ found to monitor the expression of miR-34a after cisplatin and miR-34a ta ced to lu to sensitize lung cancer cells to cisplatin [37]. It has been shown that miR-3 vas irntified as the most significantly highly expressed miRNA among TP53 alteration-c. miRNA profiles in acute myeloid leukemia with complex karyotype (CK-) T. Besrues, low expression of miR-34a and TP53 alterations predicted for chemother y re and inferior outcome in CK-AML clinically [38]. However, it was reported $t+H \mathrm{H}$ did not express p53 [39, 40] and THP-1 cells expressed mutant inactive thus ng functional p53 $[41,42]$. Therefore, the biological role of miR-34a jAML sed in our study was independent of p53 activity.

1 con on, our results demonstrated that miR-34a was lower expressed in AML compunied with the increased levels of HMGB1. Lower expression levels of HMGB1 cell apoptosis and suppressed autophagy. MiR-34a promoted cell apoptosis and

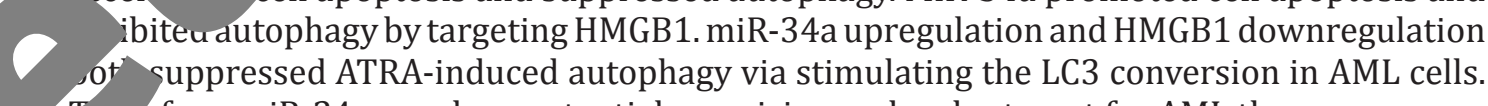
efore, miR-34a may be a potential promising molecular target for AML therapy.

\section{Acknowledgements}

This research did not receive any specific grant from funding agencies in the public.

\section{Disclosure Statement}

None. 


\section{Cellular Physiology and Biochemistry \\ Cell Physiol Biochem 2017;41:1981-1992 \\ \begin{tabular}{l|l}
\hline DOI: 10.1159/000475277 & (C) 2017 The Author(s). Published by S. Karger AG, Basel
\end{tabular} \\ Published online: April 13, 2017 www.karger.com/cpb}

Liu et al.: MiR-34a Inhibits Acute Myeloid Leukemia Cells

\section{References}

1 Lu F, Zhang J, Ji M, Li P, Du Y, Wang H, Zang S, Ma D, Sun X, Ji C: miR-181b increases drug sensitivity in acute myeloid leukemia via targeting HMGB1 and Mcl-1. Int J Oncol 2014;45:383-392.

2 Sengsayadeth S, Savani BN, Blaise D, Malard F, Nagler A, Mohty M: Reduced intensity conditioning allogeneic hematopoietic cell transplantation for adult acute myeloid leukemia in complete remission-a review from the Acute Leukemia Working Party of the EBMT. Haematologica 2015;100:859-869. Chiu CF, Weng JR, Jadhav A, Wu CY, Sargeant AM, Bai LY: T315 decreases acute myeloid leukemia cell viability through a combination of apoptosis induction and autophagic cell death. Int J Mol Sci 2016;17:1337.

-4 Ofran Y, Rowe JM: Acute myeloid leukemia in adolescents and young adults: challenging aspec haematol 2014;132:292-297.

Xu Y, Cao C, Gong X, Rong L: Inhibition of ERK5 enhances cytarabine-induced apoptos, leukemia cells. Int J Clin Exp Med 2015;8:6446-6455. Bartel DP: MicroRNAs: genomics, biogenesis, mechanism, and function. Cell 2004: Ambros V: The functions of animal microRNAs. Nature 2004; 431:350-355. Farh KK, Grimson A, Jan C, Lewis BP, Johnston WK, Lim LP, Burge C rel DP: Th spread impact of mammalian microRNAs on mRNA repression and evolution. Scic Thiebes KP, Nam H, Cambronne XA, Shen R, Glasgow SM, Cho HH, Lee SK: miR-218 is essential to establish motor neuron fate as a don Commun 2015;6:7718.

10 Aakula A, Kohonen P, Leivonen SK, Makela R, Hintsa, Mpindi JP, Ma T, Jenster G, Perala M, Kallioniemi O, Ostling P: Systema tification of microRNAs that impact on proliferation of prostate cancer cells and display nge ession in tumor tissue. Eur Urol 2016;69:1120-1128.

11 Mehta A, Zhao JL, Sinha N, Marinov GK, Map , Galimidi RP, Du X, Erikci E, Regev A, Chowdhury K, Baltimore D: The microRy micront A-212 cluster regulates hematopoietic stem cell maintenance and survival with age I ng XX3 expression. Immunity 2015;42:1021-1032.

12 Zhao XD, Lu YY, Guo H, Xie HH She , Li T, Hu SJ, Zhou L, Han YN, Liang SL, Wang X, Wu KC, Shi YQ Nie YZ, Fan DM: Mi $\quad-7 / \mathrm{NF}_{\mathrm{r}} \mathrm{dB}$ signaling regulatory feedback circuit regulates gastric carcinogenesis. J Cell Biol ?

13 Favreau AJ, McGlauflin P acute myeloid leukemia

14 Huang K, Dong B. Wang aarte Ch

\section{7} progrnstic implications. Exp Hematol Oncol 2015;5:4. cell line prolif reaung the expression level of RNA-binding protein human antigen R. Mol Med Rep 2015;1 8?

15 Adams Wal C _CJ, Inukai S, Booth CJ, Agarwal S, Rimm DL, Gyorffy B, Santarpia L, Pusztai L, Salt NM, S miR-34a silences c-SRC to attenuate tumor growth in triple-negative breast cancer. 2016;76:927-939.

an Z, - Y, Yang Q, Liu B, Wu J, Zhang Y, Yang C, Jiang Y: miR-497 and miR-34a retard lung cancer wth by -inhibiting cyclin E1 (CCNE1). Oncotarget 2015;6:13149-13163.

i J, Dong K, Lin F, Long M, Ouyang Y, Wei J, Chen X, Weng Y, He T, Zhang H: Tumor suppressor miR34 a curgets PD-L1 and functions as a potential immunotherapeutic target in acute myeloid leukemia. Cell Signal 2015;27:443-452.

Lou G, Liu Y, Wu S, Xue J, Yang F, Fu H, Zheng M, Chen Z: The p53/miR-34a/SIRT1 positive feedback loop in quercetin-induced apoptosis. Cell Physiol Biochem 2015;35:2192-2202.

Agostini M, Knight RA: miR-34: from bench to bedside. Oncotarget 2014;5:872-881. Suren D, Yildirim M, Demirpence 0, Kaya V, Alikanoglu AS, Bulbuller N, Yildiz M, Sezer C: The role of high mobility group box 1 (HMGB1) in colorectal cancer. Med Sci Monit 2014;20:530-537.

-21 Wang J, Hu X, Xie J, Xu W, Jiang H: Beta-1-adrenergic receptors mediate Nrf2-HO-1-HMGB1 axis regulation to attenuate hypoxia/reoxygenation-induced cardiomyocytes injury in vitro. Cell Physiol Biochem 2015;35:767-777. 


\section{Cellular Physiology Cell Physiol Biochem 2017;41:1981-1992 \begin{tabular}{l|l|l} 
and Biochemistry & $\begin{array}{l}\text { DOI: 10.1159/000475277 } \\
\text { Published online: April 13, } 2017\end{array}$ & $\begin{array}{l}\text { ( ) 2017 The Author(s). Published by S. Karger AG, Basel } \\
\text { www.karger.com/cpb }\end{array}$ \\
\cline { 2 - 3 }
\end{tabular}}

-22 Cheng Y, Wang H, Mao M, Liang C, Zhang Y, Yang D, Wei Z, Gao S, Hu B, Wang L, Cai Q: Escin increases the survival rate of LPS-induced septic mice through inhibition of HMGB1 release from macrophages. Cell Physiol Biochem 2015;36:1577-1586.

23 Yu Y, Xie M, He YL, Xu WQ, Zhu S, Cao LZ: Role of high mobility group box 1 in adriamycin-induced apoptosis in leukemia K562 cells. Chin J Cancer 2008;27:929-933.

24 Liu L, Yang M, Kang R, Wang Z, Zhao Y, Yu Y, Xie M, Yin X, Livesey KM, Lotze MT, Tang D, Cao L: HMGB1induced autophagy promotes chemotherapy resistance in leukemia cells. Leukemia 2011;25:23-31.

25 Lewis BP, Burge CB, Bartel DP: Conserved seed pairing, often flanked by adenosines, indicates that thousands of human genes are MicroRNA targets. Cell 2005;120:15-20. Piletic K, Kunej T: MicroRNA epigenetic signatures in human disease. Arch Toxicol 2016;9 Li G, Song Y, Zhang Y, Wang H, Xie J: miR-34b targets HSF1 to suppress cell survival in acute m: leukemia. Oncol Res 2016;24:109-116.

-28 Yang DQ, Zhou JD, Wang YX, Deng ZQ, Yang J, Yao DM, Qian Z, Yang L, Lin J, Qian J: Low is associated with poor outcome in de novo acute myeloid leukemia. Int J Lab Hemat Zauli G, Voltan R, di Iasio MG, Bosco R, Melloni E, Sana ME, Secchiero P: miR-34a in downregulation of both E2F1 and B-Myb oncogenes in leukemic cells. Clin Can

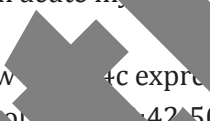
Ichimura A, Ruike Y, Terasawa K, Shimizu K, Tsujimoto G: MicroRN inhibits c repressing mitogen-activated protein kinase kinase 1 during me Mol Pharmacol 2010;77:1016-1024.

-31 Huber R, Meier B, Otsuka A, Fenini G, Satoh T, Gehrke S, Widmer D, L Gebhardt C, Fujii H, Nakashima C, Nonomura Y, Kab ma K, Dumme. Tumour hypoxia promotes melanoma growth and $m$ is via High $\mathrm{i}$ ty Group Box-1 and M2-like macrophages. Sci Rep 2016;6:29914.

32 Chen X, Wang Y, Liu J, Xu P, Zhang XM, Tian YY, Xue HMGB1 knockdown and cordycepin in the K562 hi 2015;12:4462-4468.

33 Chandrasekaran KS, Sathyanarayanan A, sufficient to suppress proliferation, mig Tumor Biol 2016;37:13155-1

-34 Samuel N, Wilson G, Id Said B, Gariepy J, Merico D, Hudso N, Mc 34A-p53 tumor suppres

-35 Chang TC, Wentzel EA, Ferlito M, Lowenstain C), broadly influe arget 2016; 7:49611-49622.

Deblols a, - ischer NW, Alexandrova R, Casallo G, Paton T, Lupien M, un D: Downregulation of HMGB1 by miR-34a is Gao Y, Wang JH: Synergistic effect of chro yeloid leukemia cell line. Mol Med Rep iferation by

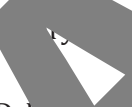
differen on of K562 cells. Mr, angana J, Kerl K, ontassot E, French LE: Raver-Shap E, Meiri E, Spector Y, Rosenfeld N, Moskovits N, Bentwich Z, Oren M: Transc tional va of miR-34a contributes to p53-mediated apoptosis. Mol Cell 2007;26:731-743.

-37 Son $\quad$ P, Su L, Wang Z, Wang Z: miR-34a sensitizes lung cancer cells to cisplatin via p53/miR34à axis. Biochem Biophys Res Commun 2016;482:22-27.

acker s AC, Cocciardi S, Kett H, Schlenk RF, Botzenhardt U, Langer C, Krauter J, Frohling S,

legelbe, ,er B, Ganser A, Lichter P, Zenz T, Dohner H, Dohner K, Bullinger L: Altered miRNA and gene $\mathrm{n}$ in acute myeloid leukemia with complex karyotype identify networks of prognostic relevance. Leununia 2013;27:353-361.

3 Wolf D, Rotter V: Major deletions in the gene encoding the p53 tumor antigen cause lack of p53 expression in HL-60 cells. Proc Natl Acad Sci U S A 1985;82:790-794.

Jiang H, Lin J, Su ZZ, Collart FR, Huberman E, Fisher PB: Induction of differentiation in human promyelocytic HL-60 leukemia cells activates p21, WAF1/CIP1, expression in the absence of p53. Oncogene 1994;9:3397-3406.

41 Traore K, Trush MA, George M Jr, Spannhake EW, Anderson W, Asseffa A: Signal transduction of phorbol 12-myristate 13-acetate (PMA)-induced growth inhibition of human monocytic leukemia THP-1 cells is reactive oxygen dependent. Leuk Res 2005;29:863-879.

42 Sugimoto K, Toyoshima H, Sakai R, Miyagawa K, Hagiwara K, Ishikawa F, Takaku F, Yazaki Y, Hirai H: Frequent mutations in the p53 gene in human myeloid leukemia cell lines. Blood 1992;79:2378-2383. 